\title{
The Historical Role of Work Social Support, Corporate Social Responsibility (CSR) and Innovation Capabilities
}

\author{
Zeeshan Rasool \\ School of Economics and Management \\ Shaanxi University of Science and Technology, Xi'an 710021, China \\ zeeshan_rasool114@hotmail.com (CA) \\ Rubab Asghar \\ National College of Business Administration \&Economics \\ Multan, Pakistan \\ Shahzad Ali Gill \\ Department of Public Administration \\ The Islamia University of Bahawalpur, Pakistan

\section{Ali Junaid Khan} \\ Institute of Business, Management \& Administrative Sciences \\ The Islamia University of Bahawalpur, Pakistan
}

\begin{abstract}
:
This study aims to observe the impact of work social system (WSS) on innovative capability through knowledge sharing process, and corporate social responsibility (CSR) through happiness feeling and job satisfaction. Several models from empirical studies were developed to test the relations such as organizational trust as moderator and happiness, knowledge sharing and job satisfaction as mediators. The data was collected in the form of questionnaires from the bank employees in the southern region of Pakistan. The study finds results consistent with the previous studies whichshow the positive relation between trust, innovation, and the supervisory support. This paper concludes that taking part in volunteer activities increases job satisfaction, happiness feeling in employees. This study has implications of promoting positive environment and culture by the managers and using organizational trust as a moderator instead of a mediator.
\end{abstract}

Keywords: Corporate social responsibility, innovation, organizational capabilities, social support, knowledge sharing, Job satisfaction. 


\section{Introduction}

\subsection{Background of the Research}

The competitive gain of any institute helps in solving the problems and tohave resources to respond to new information. Therefore, the competitionamong firms opens a window for a creative breakdown (Giustiziero et al.,2019), and organizations can get the competitive advantage by continuousinnovation and also by properly managing the changes made in strategies, they face (Ahuja \&Lampert, 2001). Hence, organizations need to innovate if they want to meet the challenges of market to gain competitive advantage. The capability of innovation is a success factor for organization (Alasoini et al., 2009), so performance and growth of any organization depends on its capability of innovation (Francis \& Bessant, 2005). Moreover, Albaladejo and Romijn (2000) concluded in a study that capability of innovation has intangible nature and measurement of it is perplexing often. The absorptive capacity of a firm may get better by sharing innovative and new ideas and by improving products of that firm (Jantunen, 2005). So, capability word is basically meant is new resources, competencies and organizational skills to meet up the challenging environment of the industry.

\subsection{Problem Statement}

As Yang et al., (2018) said resource development which adds some value is a fundamental element for innovative capability. Innovation concept means newness and it is generation as well as development of ideas for success of organizations (Chen et al., 2020). Innovation is a key tool to respond towards changes in external environment. If an organization wants to have good innovative capability, it needs a strong commitment and concern of management for gathering the innovative notions from the whole organization and also from some other resources. Companies manage the innovative capability to improve their performance and to maintain their growth. Outcomes and productivity of organizations depends on its capability to innovate, so curiosity towards this concept is increasing day by day. Thus, this research will find solution to the following questions in order to find the 
link in all these variables and alsoto establish relationship of all these variables with each other:

a. What influence WSS has on innovative capability of firm withtrust as moderator and knowledge sharing process as mediator?

b. What the CSR activities have effect on innovative capabilities with trust as moderator and happiness and job satisfaction as mediator?

Though enough literature is available on innovative capability of firm with many predictors, still the predictors being considered in this study as WS, CSR, job satisfaction, knowledge sharing, and feeling of happiness have not been considered thoroughly.

\subsection{Research Objectives}

Literature suggests that innovative capability of firm do contribute to success of organization and it's impossible without contribution and involvement of employees form all organizational levels. This study is an attempt to explain effect on work social system (WSS) and, corporate social system (CSR) events on innovative or unique competences of firm trust as moderator and job satisfaction (JS), knowledge sharing (KS), and sense of delight as mediator. Mainly the objectives are:

1) To find the effect of WSS on innovative capability of firm with trust asmoderator and knowledge sharing process as mediator

2) To observe outcome of corporate social responsibility events on innovative capability of firm, when job satisfaction and happiness level asmediator.

\subsection{Significance of Study}

Despite the increasing importance of innovative capability of firm, rare research is being conducted in this area (Sankowska, 2013). It is also discussed by Jaskyte (2020) that innovative capability help as important tool for respond to changing environment. Thus, this study is conducted tomake contribution that how firm can be 
innovative to subsist and, get excel in competitive atmosphere through WSS and activities of CSR. Thus, this research will develop a research model and connecting the WSS, Innovative capabilities, feeling of happiness, job satisfaction, and knowledge sharing process and CSR activities. This sector has a huge share in employment and its contribution in GDP is also significant. Thus, the organization who understands the role of innovative capability in performance has the competitive advantage over rivals.

\section{Literature Review}

\subsection{The Work Social Support (WSS)}

The work and family stand two interdepended ranges of life (Kaur et al., 2020; Goel, 2017). Many studies have been conducted about and indomain of work support in past due to globalization, movement of business to international and shit of social demographics (Frone et al., 2017). WSS has many important relations in past studies that also add value in this study. WSS is about intensity that if people are perceived to be helpful at workplace (Masuda, 2018). It defines that if workers get together to increase capability for dealing with stress by mingling at the workplace (Karasek et al., 1998). Karasek and other researchers also made distinction between supervisor and the coworker support. Supervisor support explains about supervisor value given to work contributed by employees and also to encourage them (Kottke and Sharafinski, 1988).

\subsection{The Knowledge Sharing Process (KSP)}

The knowledge sharing is considered vital for organizational success and,it's possible only with employee's involvement. Many scholars emphasized on sharing of knowledge as it can increase organizational learning and innovative capability (Calantone et al., 2002)

\subsection{Corporate Social Responsibility (CSR) Activities}

Corporate Social Responsibility is a part of business strategies these days; this is the reason that CSR activities are being included 
in this study to show their role in explaining the relations of this study. CSR is considered a multidimensional construct also that includes commitment towards customers, government, employees and society. As the Maignan et al. (1999) explained that if a firm wants to get edge over rivals and benefit overall, all it needs to communicate and practice the CSR activities in organization and outside the organization as well. Thus, it can be concluded that CSR activities need to be well communicated to consumeras well as employees and firm should also participate in projects that are for social welfare.

\subsection{Feeling of Happiness}

An organization's capability is innovative when it comes with new products, technology and services by sharing innovative ideas, experiences, creative processes and novelty. When employees share experiences and if they enjoy new ideas new ideas coming from jobs then they feel more committed, loyal and satisfied with that organization.

\subsection{Job Satisfaction}

Main concern of satisfaction is that what the feelings and emotions employees have about their tasks and jobs. According to Hewagama (2019), job satisfaction should be given a focused approach which actuallytells what a person expects at job and what does he receive in reality.

\subsection{Organizational Trust}

Trust is considered for success of organizations. Trust in relations in organizations is important for employee's wellbeing (Batt and Purchase, 2004). Due to globalization and other rapid changes that occurred in organizations around the world, culture became innovative rather than bureaucratic (Uzkurt et al., 2013). The culture is considered an essential element of any organization for its ultimate success by conducting operations and processes appropriately. 


\subsection{Work Social Support and Firm Innovative Capability}

The work social support is helpful as well as social practice being practices at workplace which is only possible if all employees coordinate with each other from all levels of organizations. Moreover, employees have to create the inner environment themselves for supporting the employees innovative traits (Dobni, 2010), in order to develop the new ideas and modifying the existing ones as well. Hora et al., (2013), argued that innovative capability has direct relation with social support as if social support is at its peak, innovative capability of organization is considered.

\section{Research Methodology}

\subsection{Conceptual Framework}

The conceptual or theoretical framework (figure 1) develops basis for research by developing logical relations and also making hypothesis for testing further. It explains methodology adopted for study by explaining the procedures of collecting data, specifying the sample size, and also thetechniques of analysis are described in detail. Innovative capability of organization is used as dependent variable mentioned in figure 1.

\subsection{Hypothesis Development}

H1: Organizational trust acts as moderator between work social supports (WSS) and, the knowledge allotment such as high trust strengthens this relation.

H2: Knowledge sharing process acts as mediator between work social supports (WSS) and, the administrative trust on innovative competence offirm.

H3: Happiness feeling and also job satisfaction acts as mediators betweenCSR and innovative competence or capability. 


\section{Figure 1: The Proposed Conceptual Framework}

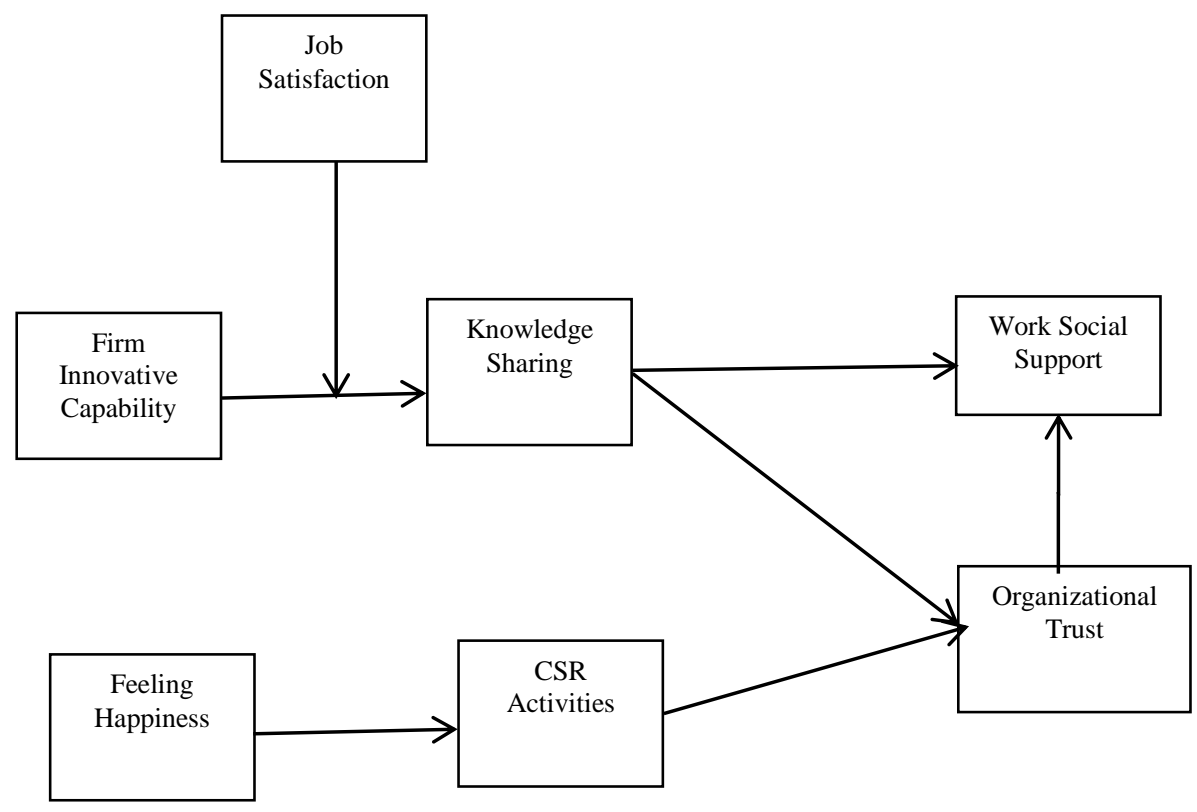

\subsection{Sample Selection}

Cross sectional data was used as confirmation for these relations of conceptual framework. Data is gathered from all officer-grades of banks to all employees of executive levels who take part in process of decision making either directly or indirectly. Banks included in this study were Summit bank, Allied Bank, Standard Chartered, Askari bank, Soneri bank, Faysal Bank, Muslim Commercial bank (MCB), Habib bank limited, and UBL. 5 branches were chosen of each bank so total 50 branches were considered for collecting data. Sampling techniques used was Purposive sampling. Employees who were thought of as included in decision making were part of respondents and include managers, cashier, departmental heads and operational manager. Therefore, the sample-size for this study is 560. Responses those were gathered are 534 which are fulfilling the required benchmarks. 


\section{Data Analyses and Interpretation}

\subsection{Descriptive Statistics}

The descriptive numbers has been calculated to present estimated means as well as standard deviations for variables. "Innovative capability showed the highest mean $(M=3.74)$, while "organizational trust" recorded the lowest mean $(M=3.60)$ mentioned in table 1. Means of all variables were above 3 that is the midpoint of research.

Table 1: The Descriptive Numbers for all Variables $(\mathrm{N}=\mathbf{2 5 0})$

\begin{tabular}{|l|l|l|l|}
\hline Variables & N & Mean & SD \\
\hline Job satisfaction & 320 & 3.72 & .65 \\
\hline Organizational trust & 320 & 3.60 & .74 \\
\hline innovative capability & 320 & 3.74 & .62 \\
\hline CSR activities & 320 & 3.13 & .71 \\
\hline Knowledge sharing & 320 & 3.14 & .67 \\
\hline Feeling happiness & 320 & 3.5 & .68 \\
\hline
\end{tabular}

\subsection{Reliability of Scales}

Reliability of all the scales was measured through the value of chronbach's alpha. Values are given in below table 2 .

Table 2: Reliability Coefficients for Items in each Variable $(\mathbf{N}=250)$

\begin{tabular}{|l|l|}
\hline Name of All Variables & $\begin{array}{l}\text { Cronbach's } \\
\text { Alpha Value }\end{array}$ \\
\hline Work social support & 0.92 \\
\hline CSR activities & 0.86 \\
\hline Knowledge sharing & 0.74 \\
\hline Feeling of happiness & .81 \\
\hline Job satisfaction & .76 \\
\hline Firm innovative & .78 \\
\hline Organizational trust & .90 \\
\hline
\end{tabular}

\subsection{Herman Single Factor Test}

If the total variance of a single factor appeared is $40 \%$ or more, it shows data is induced by CMB effect. We led EFA (Exploratory Factor Analysis) to assessment absence or presence of Herman single factor in the data. Theresults revealed that a single factor was extracted with the variance of $9.573 \%$. So, there was no evidence 
of $\mathrm{CMB}$ in the data.

\subsection{Principal Component Analysis}

\subsubsection{Work Social Support}

The principle component analysis includes linear measures in which the variables with the highest variance are removed. The PCA's aim is to bring down data. For data reduction we used the pricipal factor analysis. We checked the appropriateness of our data by evaluating the reliability of the data to perform the Factor analysis. Job Social Service efficiency was 0.671 in table 3.

Table 3: KMO and Bartlett's Test

\begin{tabular}{|l|l|l|}
\hline Kaiser-Meyer-Olkin Measure of Sampling Adequacy & 0.752 \\
\hline $\begin{array}{l}\text { Bartlett's Test of } \\
\text { Sphericity }\end{array}$ & Approx. Chi-Square & 399.515 \\
\hline & Df & 6 \\
\hline & Sig. & 00.000 \\
\hline
\end{tabular}

\subsubsection{CSR activities}

The value of Kaiser Meyer Olkin was 00.602 mentioned in table 4 . Bartlett's test of sphericity showed a weighty value. In PCA only one item was extracted to retain, explaining the variance of $85.924 \%$.

Table 4: KMO and Bartlett's Test

\begin{tabular}{|l|l|l|}
\hline Kaiser-Meyer-Olkin Measure of Sampling Adequacy & 0.602 \\
\hline $\begin{array}{l}\text { Bartlett's Test of } \\
\text { Sphericity }\end{array}$ & Approx. Chi-Square & 57.791 \\
\cline { 2 - 3 } & Df & 3 \\
\hline & Sig. & .000 \\
\hline
\end{tabular}




\subsubsection{Knowledge Sharing}

The value of Kaiser Meyer Olkin was 0.771 available in table 5 . Bartlett's test of sphericity showed a significant value. In PCA only one item was extracted to retain, explaining the variance of $68.459 \%$. After the first component, scree plot revealed a clear break.

Table 5: KMO and Bartlett's Test

\begin{tabular}{|l|l|l|}
\hline \multicolumn{2}{|l|}{$\begin{array}{l}\text { Kaiser-Meyer-Olkin Measure of Sampling } \\
\text { Adequacy }\end{array}$} & 0.771 \\
\hline $\begin{array}{l}\text { Bartlett's Test of } \\
\text { Sphericity }\end{array}$ & Approx. Chi-Square & 687.992 \\
\hline & Df & 6 \\
\hline & Sig. & .000 \\
\hline
\end{tabular}

\subsubsection{Feeling happiness}

It disclosed the presence of one component with eigenvalue greater than 1. Its KMO was 0.666 (table 6) with significant value of Barteltt's test of (Sphericity Barteltt, 1954). The value of many coefficients in correlation matrix was 0.3 or above. The total variance of happiness was 48.23 .

Table 6: KMO and Bartlett's Test

\begin{tabular}{|l|l|l|}
\hline \multicolumn{2}{|l|}{ Kaiser-Meyer-Olkin Measure of Sampling Adequacy } & 0.666 \\
\hline Bartlett's Test of Sphericity & $\begin{array}{l}\text { Approx. } \\
\text { Chi-Square }\end{array}$ & 61.102 \\
\hline & Df & 3 \\
\hline & Sig. & .000 \\
\hline
\end{tabular}




\subsubsection{Leader Helping Behavior}

The value of Kaiser Meyer Olkin was .808 in table 7, greater than the standard value .6 recommended by Kaiser $(1970,1974)$. The value of Bartlett's test of sphericity was significant which supports the correlation matrix. It was revealed by the PCA that only one item was extracted to retain, explaining the variance of $54.722 \%$.

After the first component, scree plot revealed a clear break at second component. So a single item was selected for the further investigation.

Table 7: KMO and Bartlett's Test

\begin{tabular}{|l|c|l|}
\hline \multicolumn{2}{|l|}{ Kaiser-Meyer-Olkin Measure of Sampling Adequacy } & 0.808 \\
\hline Bartlett's Test of Sphericity & Approx. Chi-Square & 924.426 \\
\hline & Df & 15 \\
\hline & Sig. & .000 \\
\hline
\end{tabular}

\subsubsection{Firm Innovative Capability}

The value of Bartlett's test of sphericity was 0.000 , which was significant. It was revealed by the PCA that two items was extracted to retain, explaining the variance of $50.624 \%$ in table 8 . After the first components, scree plot revealed a clear break. 
Table 8: KMO and Bartlett's Test

\begin{tabular}{|l|c|l|}
\hline Kaiser-Meyer-Olkin Measure of Sampling Adequacy & 0.891 \\
\hline Bartlett's Test of Sphericity & Approx. Chi-Square & 1.8263 \\
\hline & Df & 45 \\
\hline & Sig. & .000 \\
\hline
\end{tabular}

\subsubsection{Job satisfaction}

The value of Kaiser Meyer Olkin was 0.892 mentions in table 9 . The value of Bartlett's test of sphericity was significant.

Table 9: KMO and Bartlett's Test

\begin{tabular}{|l|l|l|}
\hline \multicolumn{2}{|l|}{$\begin{array}{l}\text { Kaiser-Meyer-Olkin Measure of Sampling } \\
\text { Adequacy }\end{array}$} & 0.892 \\
\hline Bartlett's Test of Sphericity & $\begin{array}{l}\text { Approx. Chi- } \\
\text { Square }\end{array}$ & 2.6293 \\
\hline & Df & 78 \\
\hline & Sig. & .000 \\
\hline
\end{tabular}

\subsection{Confirmatory Factor Analysis (CFA)}

To test the hypothesized measurement model for the data fit, CFA factor analysis is used. This study comprised of more than 10 constructs so in a single measurement model it was difficult to all constructs at a time that's why firstly we conducted CFA at individual variables separately. To report Structural Equation Modeling, mostly used fit indices are Chi-square, degree of freedom, Comparative Fit Index (CFI), Root mean square residual (RMR) Error of Approximation (RMSEA), PCLOSE etc. Further, we analyzed the discriminant and convergent validity of all the constructsto confirm the overall reliability of the measures. 


\subsection{CFA for Work Social Support}

The initial CFA results of leader's love revealed poor fit indices. Fit indices can be improved by removing indicators having factor loadings $<.50$ or removing items having covariance $>2$. So, cover factors which improved results. I again ran CFA. The results showed a significant improvement in the fit indices as now model was fit as the statistics of CMIN, RMR, CFI, RMSEA and PCLOSE were within adequate range with standardized loadings $>$ .50. The results demonstrated the value or rate of chi-square to degrees of freedom was 2.48 in table 10 . Values of model fit are given in the table 10 .

Table 10: Factors Loading of WSS

\begin{tabular}{|l|l|l|}
\hline No. & Items of WSS & Factor Loading \\
\hline 1 & WSS1 & .79 \\
\hline 2 & WSS2 & .73 \\
\hline 3 & WSS3 & .61 \\
\hline 4 & WSS4 & .69 \\
\hline 5 & WSS5 & .61 \\
\hline 6 & WSS6 & .79 \\
\hline 7 & WSS7 & .73 \\
\hline 8 & WSS8 & .61 \\
\hline 9 & WSS9 & .69 \\
\hline
\end{tabular}

\subsection{CSR Activities}

Initial results were poor, so we draw certain covariance's by following modification indices. After drawing covariance, the results demonstrated a marginal improvement in the numbers of CMIN, RMR, CFI, RMSEA, and PCLOSE of model fit. The factor loadings (table 11) of the all indicators of scale were still greater than 0.50 . 
Table 11: Factors Loading of CSR Activities

\begin{tabular}{|l|l|l|}
\hline No. & Items of CSR Activities & Factor Loading \\
\hline 1 & CSR1 & .70 \\
\hline 2 & CSR2 & .75 \\
\hline 3 & CSR3 & .74 \\
\hline 4 & CSR4 & .68 \\
\hline 5 & CSR5 & .70 \\
\hline 6 & CSR6 & .62 \\
\hline 7 & CSR7 & .63 \\
\hline 8 & CSR8 & .51 \\
\hline 9 & CSR9 & .74 \\
\hline 10 & CSR10 & .68 \\
\hline 11 & CSR11 & .70 \\
\hline 12 & CSR12 & .62 \\
\hline 13 & CSR13 & .63 \\
\hline 14 & CSR14 & .74 \\
\hline 15 & CSR15 & .68 \\
\hline 16 & CSR16 & .70 \\
\hline 17 & CSR17 & .62 \\
\hline 18 & CSR18 & .63 \\
\hline
\end{tabular}

\subsection{Knowledge Sharing Process}

In the final review, we first found a weak model fitting with the discrepancies of values CMIN, RMR, CFI, RMSEA and PCLOSE from appropriate standards while using CFA for KS which is the mediator in our research. But all scale indicators were loaded above the minimum value i.e., .50 for factor loads. To make the model more realistic, we drew covariance between the errors of the variables observed. When you run CFA again, you have the very good CMIN, RMR, CFI, RMSEA, PCLOSEand higher factor cargo values i.e., $>0.50$ in table 12 . 
Table 12: Factors Loading of KS

\begin{tabular}{|l|l|l|}
\hline No. & Items of KS & Factor Loading \\
\hline 1 & KS1 & .75 \\
\hline 2 & KS2 & .82 \\
\hline 3 & KS3 & .80 \\
\hline 4 & KS4 & .79 \\
\hline 5 & KS5 & .70 \\
\hline 6 & KS6 & .73 \\
\hline 7 & KS7 & .73 \\
\hline
\end{tabular}

\subsection{Job Satisfaction}

Finally, when we applied CFA to JS, a mediator of our case, we first saw poor model fit to deviate from the satisfactory requirements of CMIN, RMR, CFI, RMSEA, and PCLOSE. But factor loads were above the minimum value, i.e., the 50 of all scale indicators. To make the model more realistic, we drew covariance between the errors of the variables observed. When we ran again CFA and the model was excellent with fantastic CMIN, RMR, CFI, RMSEA, PCLOSE values and full loads in table 13.

\section{Table 13: Factors Loading of JS}

\begin{tabular}{|l|l|l|}
\hline No. & Items of JS & Factor Loading \\
\hline 1 & JS1 & .75 \\
\hline 2 & JS2 & .82 \\
\hline 3 & JS3 & .80 \\
\hline 4 & JS4 & .79 \\
\hline 5 & JS5 & .70 \\
\hline 6 & JS6 & .73 \\
\hline 7 & JS7 & .73 \\
\hline 8 & JS8 & .82 \\
\hline 9 & JS9 & .80 \\
\hline 10 & JS 10 & .79 \\
\hline
\end{tabular}




\subsection{Feeling of Happiness}

The result showed a standard (CMIN, RMR, CFI, RMSEA, and PCLOSE) of model fit. Now again all the factor loadings were $>.5$ in table 14.

Table 14: Factors Loading of FOH

\begin{tabular}{|l|l|l|}
\hline No. & Items of FOH & Factor Loading \\
\hline 1 & FOH1 & .63 \\
\hline 2 & FOH2 & .54 \\
\hline 3 & FOH3 & .75 \\
\hline 4 & FOH4 & .83 \\
\hline
\end{tabular}

\subsection{Organizational Trust}

Finally, first, we saw a poor fit model that corresponded to CMIN, RMR, CFI, RMSAA and PCLOSE deviated from adequate requirements when we applied CFA to organizational trust that was the moderator of our analysis. But factor loads were above the minimum value, i.e., the 50 of all scale indicators. To make the model more realistic, we drew covariance between the errors of the variables observed. When we ran again CFA and the model was excellent with fantastic CMIN, RMR, CFI, RMSEA, PCLOSE values and full loads i.e. $>0.50$ in table 15 . 
Table 15: Factor Loading of Trust

\begin{tabular}{|l|l|l|}
\hline No. & Items of trust & Factor Loading \\
\hline $\mathbf{1}$ & T1 & .75 \\
\hline $\mathbf{2}$ & T2 & .82 \\
\hline $\mathbf{3}$ & T3 & .80 \\
\hline $\mathbf{4}$ & T4 & .79 \\
\hline $\mathbf{5}$ & T5 & .70 \\
\hline $\mathbf{6}$ & T6 & .73 \\
\hline $\mathbf{7}$ & T7 & .73 \\
\hline $\mathbf{8}$ & T8 & .70 \\
\hline $\mathbf{9}$ & T9 & .71 \\
\hline $\mathbf{1 0}$ & T10 & .63 \\
\hline $\mathbf{1 1}$ & T11 & .79 \\
\hline $\mathbf{1 2}$ & T12 & .83 \\
\hline $\mathbf{1 3}$ & T13 & .78 \\
\hline $\mathbf{1 4}$ & T14 & .73 \\
\hline $\mathbf{1 5}$ & T15 & .70 \\
\hline $\mathbf{1 6}$ & T16 & .71 \\
\hline
\end{tabular}

\subsection{Firm Innovative Capability (FIC)}

When finally used CFA on advanced, dependable capacity in our research, I saw, first and foremost, that we saw a bad model fit with the correct criteria for deviated values CMIN, RMR, CFI, RMSEA andPCLOSE. But factor loads were above the minimum value, i.e., the 50 of all scale indicators. To make the model more realistic, we drew covariance between the errors of the variables observed. When we ran again CFA and the model was excellent with fantastic CMIN, RMR, CFI, RMSEA, PCLOSE values and full loads i.e. $>0.50$ in table 16 . 
Table 16: Factors Loading of IC

\begin{tabular}{|l|l|l|}
\hline No. & Items of IC & Factor Loading \\
\hline 1 & IC1 & .75 \\
\hline 2 & IC2 & .82 \\
\hline 3 & IC3 & .80 \\
\hline 4 & IC4 & .79 \\
\hline 5 & IC5 & .75 \\
\hline 6 & IC6 & .82 \\
\hline
\end{tabular}

\subsection{Construct Validity}

Validity as well as reliability is significant to check for research. Validity is of two types. One is convergent that is measured through the Average Value Extracted (AVE). Results also showed that convergent and discriminant validity was ensured as AVE > .50 and $\mathrm{MSV}<\mathrm{AVE}, \mathrm{ASV}<\mathrm{AVE}$ in table 17.

\section{Table 17: The Results of CFA}

\begin{tabular}{|l|l|l|l|l|}
\hline Measurement Model & CFI & TLI & CMIN & RMSEA \\
\hline Full Model (One Factor) & 0.57 & 0.58 & 5.1 & 0.14 \\
\hline Full Model (7 Factor) & 0.87 & 2.8 & 0.5 & 0.00 \\
\hline
\end{tabular}

\section{Conclusion}

The study had an aim to inspect the effect of WSS and also CSR on innovative capability, and to develop model to test these relations, organizational trust as moderator and happiness, knowledge sharing and job satisfaction as mediators. Model was presented and hypothesis was tested based on research questions that WSS ns CSR has effect on innovative capability ultimately. Innovative capability is the skill of an organization for exchanging ideas and producing innovative products (Branzei and Vertinsky, 2006). In support Instrumental, appraisal, emotional and informational support does play an important role. While, CSR is commitment of a firm toward employees, government, society and customers knowledge sharing includes knowledge donation as well as knowledge collection. Organization conducting VSR have happy employees that ultimately contribute in innovations. Happy 
person is morelikely to share ideas that are innovative. Hypothesis was framed on basis of literature. Hypothesis H1, H2, and H3 were supported that proved that KS, JS, and, happiness acted as mediators. Precisely WSS and CSR have effect on innovative capability with JS, FOH and KSP.

\subsection{Academic Implications}

The innovative capability (IC) is considered from a totally differentperspective in this study. Outcomes depicted the significant as well as non- significant relations. Results showed that work social system and corporate social system are antecedents of FIC and mediators affected more than moderators. Results also proved that innovative capability (IC) is vital for the victory of the institute. Innovative capability can be improved by WSS as well as through CSR but it can also be improved through sharing knowledge. It can be improved if employees are satisfied and when they are happy. Organizational trust did not show any significant impact. So, it contributes much by providing the unique relations.

\subsection{Managerial Implications}

This study has managerial implications as well as mangers should promotea positive environment and culture in organizations so that employees canshare their innovative ideas freely. It creates fairness feeling in them. It'sgood for managers who want to build and create innovative culture. In this way intellectual of employees will be enhanced as they will share ideas for making their performance better. And this is only possible by making a culture where employee's participation is ensured and team work isappreciated.

\subsection{Limitations and Future Research}

This study also has few limitations. Some limitations are listed as firm is taken here as only from perspective of innovation. While some other perspectives can also be considered. It's a cross sectional study, while longitudinal data should be collected to prove these relations that may give some different results. Only banking sector 
is considered for study, some other service sectors should be considered for future research. Some other variables can be considered for strengthening the relations between innovative capability and knowledge sharing. Validation of model should be checked by applying it on other industries as well. 


\section{References:}

1 Ahuja, G., \& Morris Lampert, C. (2001). Entrepreneurship in the large corporation: A longitudinal study of how established firms create breakthrough inventions. Strategic management journal, 22(6- 7), 521543.

2 Alasoini, T. (2009). Strategies to promote workplace innovation: a comparative analysis of nine national and regional approaches. Economic and Industrial Democracy, 30(4), 614-642.

3 Albaladejo, M., \& Romijn, H. (2000). Determinants of innovation capability in small UK firms: an empirical analysis, WP 00. 13. ECIS. Technische Universiteit Eindhoven, Eindhoven.

4 Batt, P. J., \& Purchase, S. (2004). Managing collaboration within networks and relationships.Industrial marketing management, 33(3), 169-174.

5 Branzei, O., \& Vertinsky, I. (2006).Strategic pathways to product innovation capabilities in SMEs.Journal of Business Venturing, 21(1), 75-105.

6 Calantone, R. J., Cavusgil, S. T., \& Zhao, Y. (2002).Learning orientation, firm innovation capability, and firm performance.Industrial marketing management, 31(6), 515-524.

7 Chen, Q., Wang, C. H., \& Huang, S. Z. (2020). Effects of organizational innovation and technological innovation capabilities on firm performance: evidence from firms in China's Pearl River Delta. Asia Pacific Business Review, 26(1), 72-96.

8 Dobni, C. B. (2010). The relationship between an innovation orientation and competitive strategy.International Journal of Innovation Management, 14(02), 331-357.

9 Francis, D., \& Bessant, J. (2005).Targeting innovation and implications for capability development.Technovation, 25(3), 171-183.

10 Frone, M. R., \& Parks, K. A. (2017, June). Gender Discrimination at Work, Job Dissatisfaction, and Alcohol Use: Testing the Moderating Influences of Gender and Coworker Gender Composition. In ALCOHOLISM-CLINICAL AND EXPERIMENTAL RESEARCH (Vol. 41, pp. 153A-153A). 111 RIVER ST, HOBOKEN 07030-5774, NJ USA: WILEY.

11 Giustiziero, G., Kaul, A., \& Wu, B. (2019). The dynamics of learning and competition in Schumpeterian environments. Organization Science, 30(4), 668-693.

12 Goel, A. (2017). Handling work-family conflicts: future agenda. International Journal of Manpower.

13 Hewagama, G., Boxall, P., Cheung, G., \& Hutchison, A. (2019). Service recovery through empowerment? HRM, employee performance and job satisfaction in hotels. International journal of hospitality management, 81, 73-82. 
14 Hora, M., \& Dutta, D. K. (2013). Entrepreneurial firms and downstream alliance partnerships: Impact of portfolio depth and scope on technology innovation and commercialization success. Production and Operations Management, 22(6), 1389-1400.

15 Jantunen, A. (2005). Knowledge-processing capabilities and innovative performance: an empirical study. European Journal of Innovation Management, 8(3), 336-349.

16 Jaskyte, K. (2020). Technological and Organizational Innovations and Financial Performance: Evidence from Nonprofit Human Service Organizations. VOLUNTAS: International Journal of Voluntary and Nonprofit Organizations, 1-11.

17 Karasek, R., Brisson, C., Kawakami, N., Houtman, I., Bongers, P., \& Amick, B. (1998). The Job Content Questionnaire (JCQ): an instrument for internationally comparative assessments of psychosocial job characteristics. Journal of occupational health psychology, 3(4), 322.

18 Kaur, M., \& Venkateswaran, D. C. (2020). To Study the Work Life Balance Among Working Women, Post Maternity in Banking Sector. International Journal of Management (IJM), 11(2).

19 Kottke, J. L., \& Sharafinski, C. E. (1988). Measuring perceived supervisory and organizational support. Educational and psychological Measurement, 48(4), 1075-1079.

20 Maignan, I., Ferrell, O. C., \& Hult, G. T. M. (1999). Corporate citizenship: Cultural antecedents and business benefits. Journal of the Academy of Marketing Science, 27(4), 455-469.

21 Masuda, A. D. (2018). 4 Schwartz Cultural Values: Implications for Global Work-Family Research. The Cambridge Handbook of the Global Work-Family Interface, 89.

22 Sankowska, A. (2013). Relationships between organizational trust, knowledge transfer, knowledge creation, and firm's innovativeness. The Learning Organization, 20(1), 85-100.

23 Uzkurt, C., Kumar, R., Semih Kimzan, H., \& Eminoğlu, G. (2013). Role of innovation in the relationship between organizational culture and firm performance: A study of the banking sector in Turkey. European Journal of innovation management, 16(1), 92-117.

24 Yang, Y., Choi, J. N., \& Lee, K. (2018). Theory of planned behavior and different forms of organizational change behavior. Social Behavior and Personality: an international journal, 46(10), 1657-1671. 